\title{
Rancang Bangun Sistem Informasi Penjualan Sparepart Motor Pada Bengkel Vinensi Motor Berbasis Web Guna Meningkatkan Penjualan dan Promosi Produk
}

\author{
Aris Sudianto ${ }^{1 *}$, Hamzan Ahmadi2 ${ }^{2}$ Alimuddin ${ }^{3}$ \\ 1,2 Program Studi Teknik Informatika, Universitas Hamzanwadi \\ ${ }^{3}$ Program Studi Teknik Komputer, Universitas Hamzanwadi \\ *sudianto166@gmail.com
}

\begin{abstract}
Abstrak
Bengkel Vinensi Motor merupakan perusahaan dagang bergerak di bidang penjualan sparepart sepertii kenalpot, lampu motor, busi, spion dan lain - lain, dimana proses promosi dan penjualannya masih bersifat konvensional. Artinya pelanggan harus mendatangi bengkel untuk dapat melakukan pembelian produk. Rancang bangun sistem informasi penjualan di bengkel Vinensi Motor merupakan langkah untuk meningkatkan penjualan dan promosi produk sehingga dapat memberikan keuntungan bagii bengkel itu sendiri. Tujuan membangun sistem informasi penjualan sparepart ini pelanggan dapat melakukan pemesanan produk tanpa harus datang bengkel Vinensi Motor, pihak bengkel pun dapat mengatasi masalah pengolahan produk, pengolahan pemesanan sehingga memberikan kemudahan kepada konsumen untuk mendapatkan informasi tentang produk yang tersedia pada bengkel Vinensi Motor. Sistem ini dirancang menggunakan bahasa program HTML, PHP dengan menggunakan database MySQL sedangkan untuk editornya sendiri menggunakan Sublime text. Hasil dari penelitian ini adalah dengan diimplementasikan sistem informasi penjualan sparepart ini dapat digunakan sebagai sarana promosi penjualan yang dapat diakses dimanapun dan kapanpun, proses pembelian dapat secara langsung tanpa harus datang ke toko, serta dapat mempermudah proses transaksi pembelian produk, sehingga dapat meningkatkan penjualan dari bengkel Vinensi Motor itu sendiri.
\end{abstract}

Kata kunci : sistem informasi, Sparepart, Bengkel, PHP, Mysql

\begin{abstract}
Vinensi Motor Workshop is a trading company engaged in the sale of spare parts such as oil, motorcycle lights, spark plugs, mirrors and others, where the promotion and sales process is still conventional. This means that customers must go to a garage to be able to make product purchases. The design of the sales information system in the Vinensi Motor workshop is a step to increase sales and product promotions so that it can benefit the workshop itself. The purpose of building this spare part sales information system is that customers can order products without having to come by Vinensi Motor workshop, the workshop can overcome the problem of product processing, order processing so as to make it easy for consumers to get information about the products available at Vinensi Motor's workshop. This system is designed using HTML, PHP using MySQL database while the editor uses Sublime text. The results of this research are the implementation of this spare part sales information system can be used as a sales promotion tool that can be accessed anywhere and anytime, the purchase process can be directly without having to come to the store, and can simplify the product purchase transaction process, so as to increase sales from the workshop Vinensi Motor itself.
\end{abstract}

Keywords: information systems, spare parts, repair shops, PHP, Mysql

\section{Pendahuluan}

Bengkel Vinensi motor merupakan toko sparepart sepeda motor yang cukup berkembang, dengan semakin bertambahnya volume kendaraan secara tidak langsung kebutuhan suku cadang motor juga dibutuhkan semakin banyak, disamping itu data dan transaksi yang semakin banyak menimbulkan beberapa kelemahan dan masalah dalam penjualan sparepart motor di Bengkel Vinensi 
Motor, diantaranya dalam pemasarannya masih manual yaitu pembeli harus langsung datang ke toko Bengkel Vinensi untuk memilih barang yang ingin dibelinya, disini menjadi masalah untuk bidang pemasaran pada Bengkel Vinensi Motor. Sparepart yang dijual pada Bengkel Vinensi Motor antara lain untuk merk motor Honda, Yamaha, Kawasaki, Suzuki, dan adapun merk lainnya. Seiring dengan semakin pesatnya pemanfaatan teknologi informasi saat ini terutama dalam bidang usaha, maka perancangan teknologi informasi sangat diperlukan bagi pemilik usaha untuk meningkatkan daya saing dan mempermudah pengolahan data transaksi maupun persediaan barang. Demikian halnya dalam penjualan sparepart motor pada Bengkel Vinensi yang belum memiliki suatu sistem terkomputerisasi yang dapat mengolah data transaksi penjualan dan persediaan barang yang berguna untuk mempermudah dalam membuat atau merekap laporan transaksi penjualan dan mempermudah dalam pencatatan maupun mengetahui stock barang yang tersedia dan barang yang terjual.

\section{Tinjauan Pustaka}

\subsection{Penelitian Terkait}

Menurut Faizal Adi Pradana pada penelitiannya yang berjudul "Sistem Informasi Penjualan Spare Part Sepeda Motor Berbasis Web Mobile Di Dd Motor Lasem". Dimana penelitian ini membahas tentang perancangan penjualan sparepart sepeda motor berbasis web mobile untuk membatu pemasaran toko DD Motor Lasem lebih berkembang sekaligus bisa memudahkan para karyawan DD Motor Lasem dalam mengolah data dan memudahkan pelanggan untuk bisa membeli sparepart motor tidak hanya langsung datang ke toko DD Motor Lasem tapi dapat juga di akses melalui web.

Menurut Dimi Rizkyadi pada penelitiannya yang berjudul "Sistem Informasi Pelayanan Jasa Service Dan Penjualan Suku Cadang Sepeda Motor Pada Bengkel Greaf Berbasis Desktop". Dimana Penelitian ini membahas tentang pembuatan suatu program yang berbasis desktop pada Bengkel Greaf yang mampu meminimalisir kesalahan dalam pencatatan data barang masuk dan retur barang. mempercepat proses penjualan dikarenakan pencarian data barang sudah terigentrasi dan tersimpan didalam suatu database. pembuatan laporan menjadi lebih mudah dikarenakan semua data transaksi bengkel yang tersimpan di database.

Dilihat dari kesamaan dari penelitian yang dilakukan Faizal Adi Pradana dan Dimi Rizkyadi maupun oleh penulis yang mengangkat judul "Rancang Bangun Sistem Informasi Penjualan Sparepart Motor Pada Bengkel Vinensi Motor Berbasis Web Sebagai Guna Meningkatkan Penjualan dan Promosi Produk".sama-sama membahas tentang sistem perancangan penjualan sparepart motor yang bertujuan untuk membantu kinerja dari bengkel tersebut dalam pemasaran hingga membuat suatu sistem yang mampu membuat pekerjaan lebih efektif dan efisien dari data stok barang, data transaksi 
penjualan dan pembelian, hingga laporanlaporan yang dibutuhkan.

Menurut Sudianto Aris, dalam penelitiannya yang mengangkat manfaat website sebagai media promosi menyatakan bahwa dengan menggunakan website sebagai media sarana promosi wisata budaya dapat mengurangi biaya promosi yang digunakan dalam mempromosikan object wisata budaya khususnya di kabupaten lombok timur.[1] website tidak hanya dapat digunakan untuk promosi ataupun penjualan, namun website juga dapat dijadikan sebagai media sistem informasi untuk pendataan, sebagai salah satu contohnya adalah pendataan tracerstudy.[2]

\subsection{Landasan Teori}

\section{Sistem informasi}

Menurut Mcleod (2001) Sistem Informasi merupakan sistem yang mempunyai kemampuan untuk mengumpulkan informasi dari semua sumber dan menggunakan berbagai media untuk menampilkan informasi. Sistem informasi merupakan sebuah sistem di dalam suatu organisasi yang mempertemukan berbagai kebutuhan proses pengolahan transaksi harian, membantu dan mendukung seluruh kegiatan operasi, bersifat manajerial dari suatu organisasi serta membantu memperlancar penyediaan laporan yang dibutuhkan.

Dengan menerapkan sistem informasi, dapat mempermudah pengguna dalam melakukan segala hal secara lebih efektif dan efisiensi waktu, salah satu contohnya adalah pencarian lokasi tambal ban di lombok timur, dengan menerapkan sistem informasi berbasis geografis[3]

\section{Penjualan}

Penjualan adalah suatu usaha yang terpadu untuk mengembangkan rencana - rencana strategis yang diarahkan pada usaha pemuasan kebutuhan dan keinginan pembeli, guna mendapatkan penjualan yang menghasilkan laba

\section{Sparepart}

Sparepart diterjemahkan kedalam bahasa Indonesia yaitu suku cadang, penulis juga mempunyai kesimpulan bahwa suku cadang disini adalah komponen-komponen yang ada pada motor.

\section{Website}

Website adalah lokasi di internet yang menyajikan kumpulan informasi sehubungan dengan profil pemilik situs. Website adalah suatu halaman yang memuat situs-situs web page yang berada di internet yang berfungsi sebagai media penyampaian informasi, komunikasi, atau transaksi Bersifat statis apabila isi informasi website tetap, jarang berubah, dan isi informasinya searah hanya dari pemilik website. Bersifat dinamis apabila isi informasi webside selalu berubah-ubah, dan isi informasinya interaktif dua arah berasal dari pemilik serta pengguna webside[4][5] 


\section{Web Server}

Sebuah software yang memberikan layanan berbasi data berfungsi untuk melakukan transfer berkas permintaan berupa berkas teks, video, gambar, file dan lain-lain. Menurut Simarmata (2010:88) "Web Server adalah potongan perangkat lunak yang mendukung berbagai protocol Web, seperti HTTP, HTTPS, dan lainlain untuk memproses permintaan client". Menurut Sibero (2013:11) "Web Server adalah sebuah komputer yang terdiri dari perangkat keras dan perangkat lunak". Sedangkan Menurut Arief (2011:19) "Web server adalah program aplikasi yang memiliki fungsi sebagai tempat menyimpan dokumen-dokumen web".[4][5] Berdasarkan pendapat yang dikemukanan diatas dapat disimpulkan bahwa, Web Server adalah potongan perangkat lunak yang memiliki fungsi sebagai tempat menyimpan dokumen-dokumen web dengan dukungan berbagai protocol web dan lain-lain untuk memproses permintaan client[6][7]

\subsection{Tahapan Penelitian}

Sistem yang akan dikembangkan nantinya mampu menjawab segala permasalahan yang ada, diantaranya dapat dilihat pada Tahapan penelitian yang digambarkan dalam bentuk bagan Flowmap di bawah ini :

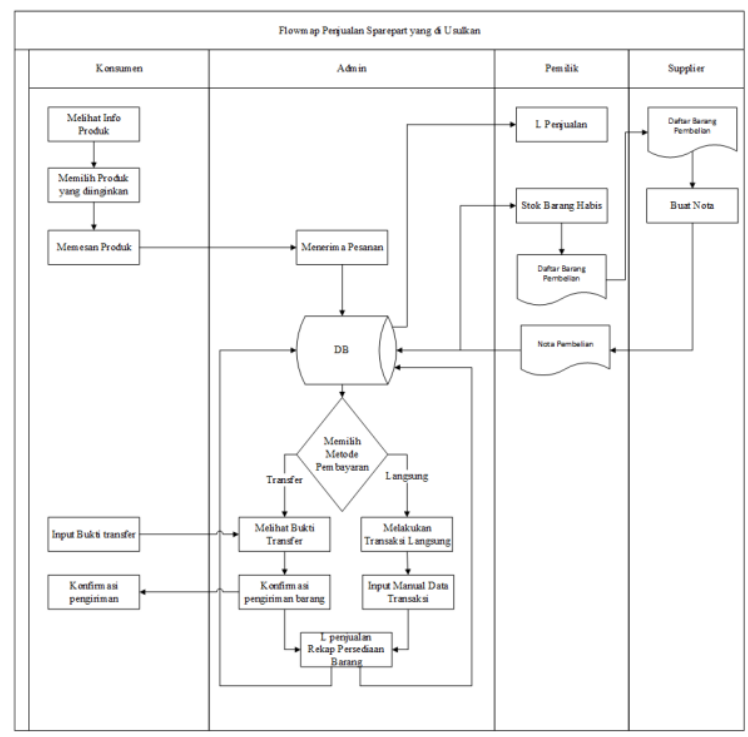

Gambar 1. Tahap Penelitian

Pada Tahap penelitian tersebut alur dari penjualan hingga pembelian barang dari supplier. Konsumen akan mencari barang yang diinginkan jika barang tersebut ada maka akan melakukan pemesanan dan admin akan memproses pemesanan barang tersebut. Disini admin akan mengecek stok barang kosong dan pemilik akan mengirim daftar pemesanan barang ke supplier, jika barang tersebut terpenuhi maka supplier akan memberikan nota pembelian

\section{Metode Penelitian}

\subsection{Metode yang dilakukan pada perancangan sistem Informasi} Penjualan.

Beberapa tahapan Metode yang dapat digunakan untuk merancang sistem Informasi penjualan sparepart ini antar lain :

1. Pengumpulan informasi dan bahan - bahan penelitian yang berhubungan dengan bengkel Vinensi Motor dan sparepare Motor. 
2. Tahap Analisis, pada tahap ini dari beberapa sumber tentang sistem informasi penjualan sparepart motor yang yang pernah diteliti oleh yang lain dan dengan penelitian yang akan dilakukan, selanjutnya dilakukan suatu analisis untuk ditentukan seperti apa sja yang akan dimunculkan pada sistem informasi penjualan sparepart motor pada bengkel Vinensi.

3. Tahap desain dan proses, pada tahapan ini bahan yang sudah dipilih dilakukan proses desain baik dalam bentuk desain pemodelan maupun desain user interface menggunakan editor Sublime Text.

4. Tahap Implementasi, pada tahapan ini dilakukan proses ujicoba dari sistem informasi penjualan yang telah dibuat, yang selanjutnya jika sistem telah berhasil berjalan sesuai kebutuhan, maka sistem dapat diimplementasikan pada Bengkel Vinensi Motor, yang diharapkan dengan sistem ini dapat membantu meningkatkan penjualan dan juga promosi dari bengkel Vinensi.

\subsection{Lokasi Penelitian}

Penelitian ini dilakukan dengan mengumpulkan sumber data yang di ambil Bengkel Vinensi Motor yang beralamat di Jln. Cut Nyak Dien, Pancor Bermi, Kecamatan Selong, Kabupaten Lombok Timur.

\subsection{Teknik Pengumpulan Data}

Teknik pengumpulan data yang di gunakan dalam proses pembuatan sistem informasi Penjualan Sparepart adalah:

1. Observasi.

Teknik observasi dalam penelitian ini yaitu dengan cara pengumpulan data yang dilakukan pada saat melakukan penelitian dan pencatatan data-data secara langsung terhadap Bengkel Vinensi Motor.

2. Wawancara.

Metode yang dilakukan dengan cara melakukan wawancara secara langsung dengan pihak-pihak terkait. Kegiatan yang dilakukan diantaranya tanya jawab secara langsung kepada pemilik Bengkel Vinensi Motor tentang masalah yang di hadapi khususnya tentang masalah penjualan pada Bengkel Vinensi Motor.

\section{Hasil dan Pembahasan}

Sistem informasi penjualan ini terdiri dari beberapa tampilan yang masing-masing tampilan/halaman mempunyai fungsi-fungsi tersendiri baik dalam penginputan maupun penyimpanan data. Perancangan halaman form yang terdapat dalam Sistem Informasi Penjualan Sparepart Motor pada Bengkel Vinensi Motor adalah sebagai berikut : 
1. Halaman Katalog Produk

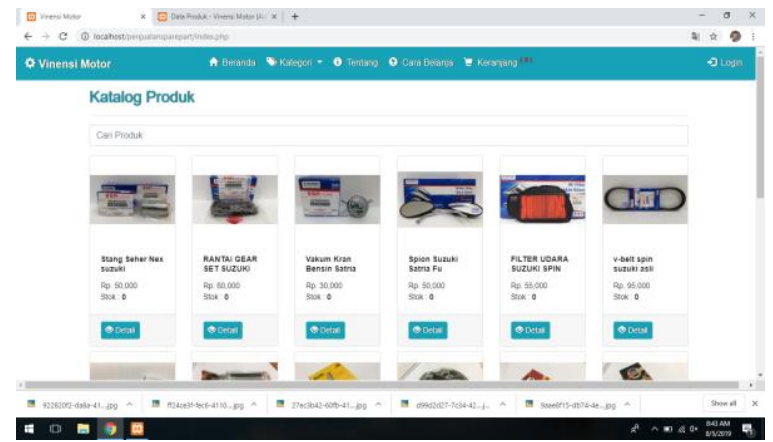

Gambar 2. Halaman Produk

Dalam halaman ini berisi katalog produk yang ada pada bengkel tersebut, user dapat dengan mudah memilih produk sesuai ke inginan mereka karna pada halaman ini terdapat form pencariian yang dapat memudahkan user dengancepat menemukan barang yang diinginkannya.

2. Halaman Keranjang

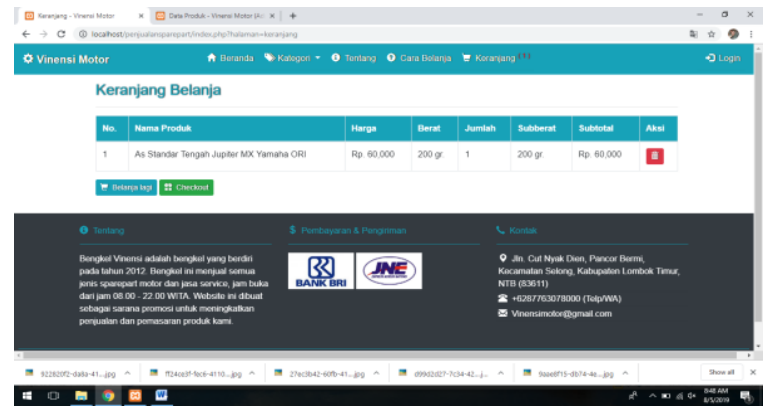

Gambar 3. Halaman Keranjang

Pada halaman keranjang ini user dapat menaruh produk yang kan di beli sebelum melakukan transaksi, user juga bisa menghapus produk yang ada dalam keranjang tersebut jika tidak jadi ingin membeli barang tersebut.

\section{Halaman Checkout}

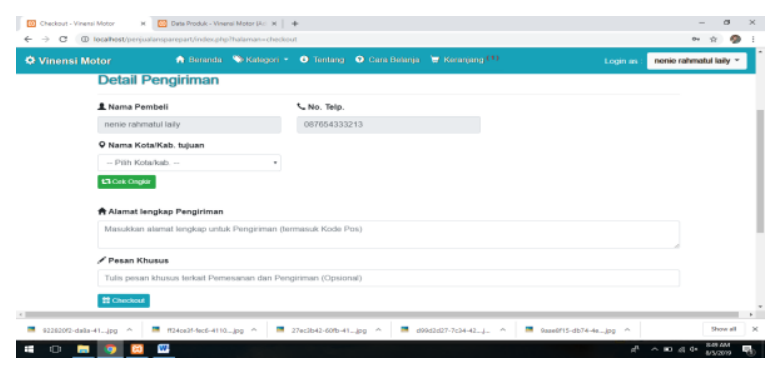

Gambar 4. Halaman Checkout

Pada Halaman ini terdapat total dari semua pembelian. User dapat mengisi alamat lengkap agar mempermudah dalam pengiriman barang dan user akan memelih kota/kabupaten agar dapat mengetahui berapa biaya kirim yang harus dibayar.

\section{Halaman Nota}

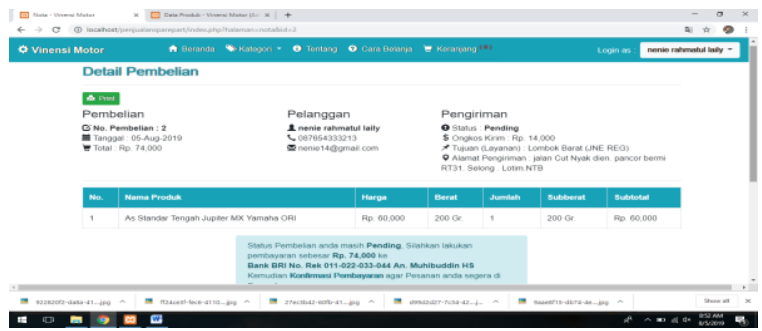

Gambar 5. Halaman Nota

Pada halaman ini berisi detail pembelian dimana user dapat melihat nomer rekening yang akan dituju untuk pembayaran, jika user blum mentransfer jumlah uang yang di cantumkan maka status pembelian masih pending. Kama harus mentranfer terlebiih dahulu agar barang yang diinginkan bias diproses.

\section{Halaman Pembayaran}

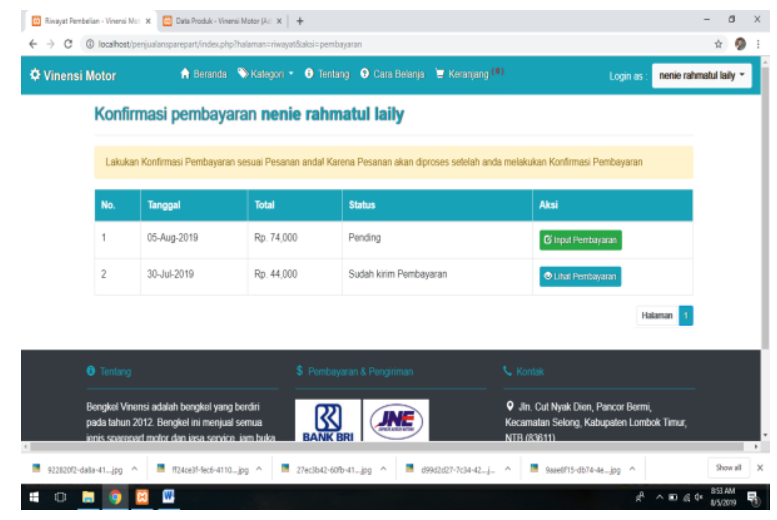

Gambar 6. Konfirmasi Pembayaran

Pada halaman ini terdapat konfirmasi pembayaran yang harus dilakukan oleh user, jika user tidak menginputkan bukti pembayaran yang dilakukan status pengiriman akan tetap pending. 
Apabila bukti transaksi sudah diinputkan maka user akan menunggu konfirmasi dari admin terlebih dahulu.

\section{Halaman Form Konfirmasi Pembayaran}

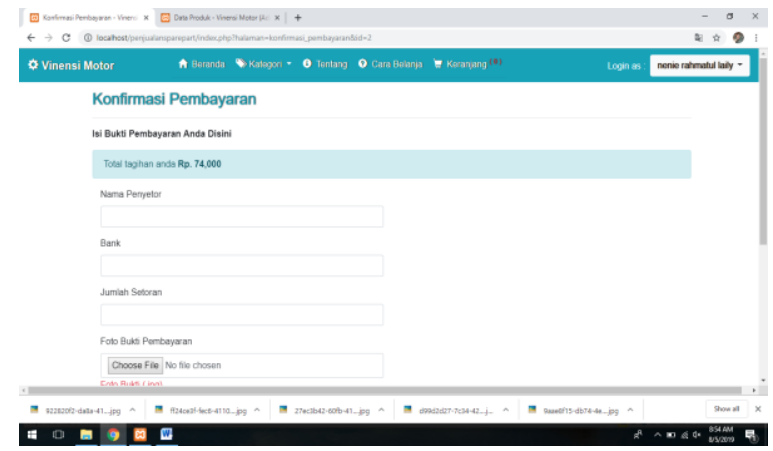

Gambar 7. Input Bukti Pembayaran

Pada halaman ini terdapat form yang akan diisi oleh user agar untuk mengetahui apakah user benar-benar melakukan teransaksi sesuai ketentuan yang ada.

\section{Halaman Validasi Pembayaran}

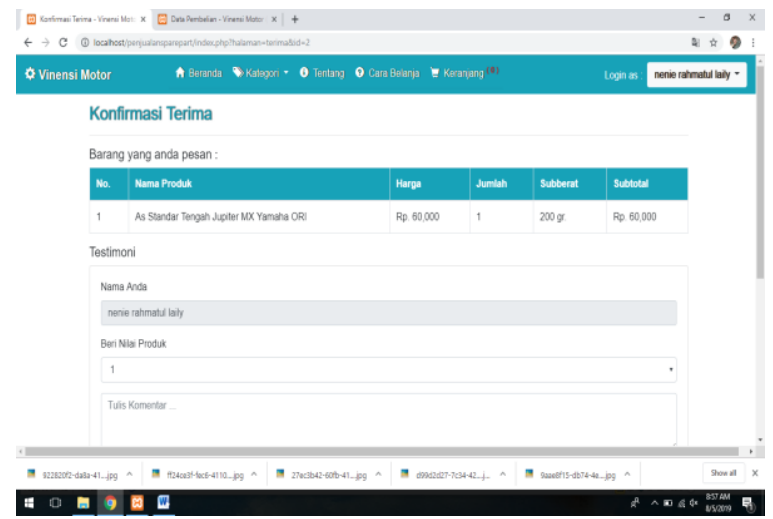

Gambar 8. Validasi Pembayaran

Pada halaman ini admin akan memvalidasi pembayaran dari user, jika bukti transaksi sesuai maka admin akan langsung mengganti status pending menjadi sedang di proses atau sudah dikirim, apabila status barang sudah dikirim makan admin akan mengirim nomer resi barang agar user dapat melacak lokasi barang.

\section{Kesimpulan}

Berdasarkan penelitian yang telah dilakukan hingga penyelesaian pembuatan Sistem Informasi Penjualan Sparepart Motor pada Bengkel Vinensi Motor, penulis menarik beberapa kesimpulan yaitu bahwa dengan Aplikasi web penjualan sparepart pada Bengkel Vinensi Motor yang dibuat ini dapat memberikan solusi dalam permasalahan yang timbul di antaranya :

- Dengan adanya sistem informasi ini, dapat mempercepat proses penyelesaian pekerjaan dalam mengolah data yang ada agar lebih akurat, efektif dan efisien sehingga dapat menghemat waktu dan meningkatkan kinerja karyawan Bengkel Vinensi Motor.

- Dengan adanya Sistem Informasi ini, dapat meminimalisir kesalahan dalam pencatatan data barang masuk dan barang keluar.

- Dengan adanya Sistem Informasi ini dapat mempercepat proses penjualan dikarenakan pencarian data barang sudah terigentrasi dan tersimpan didalam suatu database.

- Dengan adanya sistem informasi ini diharapkan pembuatan laporan menjadi lebih mudah dikarenakan semua data transaksi bengkel yang tersimpan di database.

- Sistem yang dibangun dapat menampilkan secara online tentang layanan dan produk pada Bengkel Vinensi Motor secara luas. 


\section{Daftar Pustaka}

[1] Sudianto Aris, "Penerapan Website Sebagai Sarana Promosi Wisata Budaya pada Kabupaten Lombok Timur," Infotek J. Inform. dan Teknol., vol. 1Sudianto, no. 1, pp. 11-17, 2018.

[2] M. Saiful and S. Aris, "Penerapan Sistem Informasi Tracer Study untuk Mengetahui Tingkat Kontribusi Perguruan Tinggi dengan Kompetensi Lulusan ( Studi Kasus Fakultas Teknik Universitas Hamzanwadi )," J. Inform. dan Teknol., vol. 2, no. 1, pp. 43-52, 2019.

[3] L. K. W. Sudianto Aris, Nurhidayati, "Penerapan Sistem Informasi Geografis Untuk Pemetaan Bengkel Tambal Ban di Kecamatan Selong Kabupaten Lombok Timur," Infotek J. Inform. dan Teknol., vol. 3, no. 1, pp. 51-57, 2020.

[4] J. S. Aris Sudianto, "Website as Foundation Information Media under the auspices of Website as Foundation Information Media under the auspices of Nahdlatul Wathan," J. Phys., vol. 1539, no. 012024, pp. 3-8, 2020.

[5] D. Octavia and D. D. Ratna, "SISTEM INFORMASI PENJUALAN SPAREPART MOTOR BERBASIS WEB PADA PT . XYZ," pp. 1-7, 2017.

[6] R. P. Hastanti, B. Eka, P. Indah, and U. Wardati, "Sistem Penjualan Berbasis Web ( E-Commerce ) Pada Tata Distro Kabupaten Pacitan," vol. 3, no. 2, pp. 19, 2015.

[7] D. Rizkyadi, "SISTEM INFORMASI PELAYANAN JASA SERVICE DAN PENJUALAN SUKU CADANG SEPEDA MOTOR," pp. 1-17, 2015.

[8] M. Bidakara, G. Subroto, and J. Selatan, "Strategi promosi penjualan," vol. 4, no. 11, pp. 64-74, 2016. 